\title{
Conocimientos de normas de bioseguridad en enfermeros de un centro quirúrgico al inicio de la pandemia por COVID-19 en Andahuaylas, Perú
}

\author{
Knowledge of biosafety standards in surgical center nurses at beginning of the \\ COVID-19 pandemic in Andahuaylas, Peru
}

\author{
Golda Cordova-Herediaa,2,a , Cesar Hurtado-Altamirano ${ }^{1,3, b}$, Nieves Puma-Cárdenas, 1,4,b, \\ Edith Giraldo-Sánchez ${ }^{1,5, b}$ \\ ${ }^{1}$ Universidade Cidade de Sâo Paulo. Sâo Paulo, Brasil. \\ ${ }^{2}$ Universidad Andina del Cusco. Cusco, Perú. \\ ${ }^{3}$ Hospital Docente Hugo Pesce. Andahuaylas, Perú. \\ ${ }^{4}$ Centro de Salud Velille. Cusco, Perú. \\ ${ }^{5}$ Centro de Salud Lares. Cusco, Perú. \\ ${ }^{a}$ Licenciada en enfermeria, ORCID: https://orcid.org/0000-0001-6315-1787 \\ ${ }^{\mathrm{b}}$ Licenciada(0) en enfermería
}

An Fac med. 2020;81(3):370-1. / DOI: https://doi.org/10.15381/anales.v81i3.18114

Correspondencia:

Golda Córdova Heredia

goldaheredia84@gmail.com

Recibido: 25 de abril 2020

Aprobado: 15 de mayo 2020

Publicación en línea: 30 de septiembre 2020

Conflictos de interés: Los autores declaran no tener conflictos de interés

Fuente de financiamiento:

Autofinanciado

Citar como: Córdova-Heredia G, Hurtado-Altamirano C, Puma-Cárdenas N, Giraldo-Sánchez E. Conocimientos de normas de bioseguridad en enfermeros de un centro quirúrgico al inicio de la pandemia por COVID-19 en Andahuaylas, Perú. An Fac med. 2020;81(3):370-1. DOI: https://doi. org/10.15381/anales.v81i3.18114.

\section{Sr. Editor,}

El inicio de la epidemia por COVID-19 en el Perú se dio el 6 de marzo del 2020 en la ciudad de Lima ${ }^{(1)}$, con una lenta progresión hacia las ciudades de la sierra del Perú, siendo Andahuaylas una de las últimas ciudades en registrar casos, con el primer caso reportado el 31 de marzo. Estas demoras dieron tiempo para que las instituciones de salud implementen o mejoren los protocolos de atención y demás medidas de bioseguridad. Así, el Estado peruano aprobó el 8 de marzo de 2020 el documento técnico para atención y manejo clínico de pacientes COVID-19 ${ }^{(2)}$, dirigido a disminuir la propagación e impacto de la epidemia; pero una parte importante de todo el proceso consistía en tener personal capacitado desde un inicio respecto a normas generales de bioseguridad que permitan una fácil implementación de dichas normativas. No obstante, el nivel de conocimiento en normas de bioseguridad no es conocido; por ello, nuestro objetivo fue el de evaluarlo en los enfermeros del centro quirúrgico de un hospital del Perú, en un escenario previo a la pandemia por COVID-19.

Para ello, realizamos un estudio descriptivo transversal en el Hospital Docente Hugo Pesce de Andahuaylas (único hospital del Ministerio de Salud del departamento), incluyendo 30 enfermeros que laboraban en centro quirúrgico, a quienes se les invitó a participar del estudio realizado del $1^{\circ}$ al 15 de febrero de 2020. Se incluyeron a todos los enfermeros que aceptaron participar del estudio y que laboraban en centro quirúrgico durante el periodo de estudio.

Medimos el nivel de conocimiento de las normas de bioseguridad empleando una escala validada en un estudio previo ${ }^{(3)}$, y que abordaba tres aspectos: información general sobre los conocimientos, barreras protectoras y, eliminación de residuos. El personal de enfermería tuvo una edad promedio de 43,8 +/- 7,9 años, el promedio del tiempo de servicio fue de $16,8+/-7,6$ años, y el promedio del tiempo de experiencia en centro quirúrgico fue de $14,3+/-6,2$ años.

Las secciones evaluadas y el porcentaje de respuesta para cada una se presentan en la tabla 1. Las preguntas con menor porcentaje de respuestas correctas fueron sobre "principios de bioseguridad" ( $0 \%$ correctas), y "duración del lavado de mano" (0\% correctas); en esta última, todas las respuestas indicaron el tiempo de lavado de manos social (20 a 30 segundos) y no el tiempo requerido para un lavado de manos clínico. El promedio de edad, el tiempo de servicio o el tiempo de experiencia en centro quirúrgico no tuvieron diferencias en el nivel de conocimiento $(p>0,05)$. 
Tabla 1. Respuestas correctas por cada ítem evaluado para medir el nivel de conocimientos en enfermeros de un centro quirúrgico, Andahuaylas, Perú, 2020.

\begin{tabular}{lcc}
\hline Definición de bioseguridad & $27(93 \%)$ \\
\hline Principios de bioseguridad & $0(0 \%)$ \\
\hline Técnica de lavado de manos & $27(93 \%)$ \\
\hline Duración del lavado de manos clínico & $0(0 \%)$ \\
\hline Uso de guantes & $25(86 \%)$ \\
\hline Proceso para calzarse los guantes & $24(83 \%)$ \\
\hline Anteojos de protección: uso & $29(100 \%)$ \\
\hline Anteojos de protección: ambientes & $6(20 \%)$ \\
\hline Cobertura de la mascarilla & $28(97 \%)$ \\
\hline Uso del gorro & $2(7 \%)$ \\
\hline Colocación de la indumentaria & $21(72 \%)$ \\
\hline Uso de botas & $12(41 \%)$ \\
\hline Uso del mandilón & $12(41 \%)$ \\
\hline Desinfección: clasificación & $15(52 \%)$ \\
\hline Desinfectantes: protección & $22(76 \%)$ \\
\hline Residuos intrahospitalarios: clasificación & $26(90 \%)$ \\
\hline Residuos intrahospitalarios: desecho & $27(93 \%)$ \\
\hline
\end{tabular}

Estos resultados nos muestran que no todos lograron identificar los principios generales de la bioseguridad: su aplicación universal, el uso de barreras, y el control de residuos ${ }^{(4)}$. Por el contrario, el 93\% de nuestros encuestados conocían la definición de bioseguridad. Es probable que ante la pandemia por COVID-19 los principios de bioseguridad sean más socializados y puedan mejorar en este aspecto. Respecto a la aplicación específica de la bioseguridad, nuestro estudio mostró vacíos en el conocimiento en varias áreas. Durante la pandemia por COVID-19 se ha incidido ampliamente en el lavado de manos como una medida de bioseguridad que limitará la propagación del virus, y si bien el tiempo recomendado para el lavado de manos es de 20 segundos, tiene diferencias según las indicaciones, siendo el más prolongado el lavado de manos quirúrgico de no menos de 5 minutos, seguido por el lavado clínico de 1 minuto ${ }^{(5)}$, y el más breve: el lavado de manos social que se promueve en la pandemia.
Por último, uno de los aspectos que más se difunde durante la pandemia COVID-19 es el uso de equipos de protección personal (EPP) para el personal de salud ${ }^{(6)}$. En nuestra evaluación, el rendimiento fue mixto: más del $70 \%$ conocía sobre el uso y el proceso de calzado de guantes, así como la mascarilla, uso de anteojos de protección, o el proceso de colocación de la indumentaria; pero al tratarse de personal que labora en centro quirúrgico, estos conceptos deberían ser más altos. El uso de EPP se ha socializado ampliamente y es el principal motivo de reclamo de varios profesionales debido a la falta de equipamiento en plena pandemia por COVID-19 en el Perú ${ }^{(7,8)}$; asimismo, se precisa de una amplia instrucción sobre su adecuado uso.

Consideramos importante realizar el ejercicio regular de medición del conocimiento de las normas de bioseguridad que tienen los enfermeros para disminuir sus riesgos, en particular estando en plena pandemia por COVID-19 donde se re- quiere una adecuada capacitación sobre la aplicación de las normas de bioseguridad.

Agradecimientos. A la Lic. Veronica Cecilia Calbo de Medeiros por la orientación y asesoría para la ejecución de la investigación.

\section{REFERENCIAS BIBLIOGRÁFICAS}

1. Plataforma digital del Estado Peruano [Internet]. Ministra Hinostroza pidió tener confianza en el sistema de salud tras confirmarse primer caso de coronavirus en perú, 2020 [Fecha de acceso: 3 de mayo 2020]. Disponible en: https://www.gob.pe/institucion/minsa/noticias/86983-ministra-hinostrozapidio-tener-confianza-en-el-sistema-de-salud-trasconfirmarse-primer-caso-de-coronavirus-en-peru

2. Plataforma digital del Estado Peruano [Internet]. Resolución Ministerial Nº84-2020-MINSA. Documento Técnico: Atención y Manejo Clínico de Casos de COVID-19 [Fecha de acceso: 3 de mayo 2020]. Disponible en: https://www.gob.pe/institucion/ minsa/normas-legales/455338-084-2020-minsa

3. Castilla Aburto JV, Sarmiento Meza NL. Conocimientos y prácticas de las normas de bioseguridad del profesional de enfermeria de la unidad de recuperación posanestésica del Hospital Guillermo Almenara Irigoyen, 2017 [Tesis para obtener el grado de Segunda Especialidad como Especialista en Enfermeria en Cuidados Quirúrgicos]. Lima: Universidad Peruana Unión.

4. Vargas Campos RV. Principios de bioseguridad y su aplicación en centro quirúrgico, 2019 [Tesis para optar por el grado de Especialista en Centro Quirúrgico]. Cajamarca: Universidad Nacional de Cajamarca.

5. Instituto Regional de Enfermedades Neoplásicas [Internet]. Guía: Lavado de manos clínico y quirúrgico, 2012 [Fecha de acceso: 3 de mayo 2020]. Disponible en: http://www.irennorte.gob.pe/pdf/ rdirectorial/209-2012.pdf

6. Organización Panamericana de la Salud [Internet] Requerimientos para uso de equipos de protección personal (EPP) para el nuevo coronavirus (2019ncov) en establecimientos de salud, 2020 [Fecha de acceso: 3 de mayo 2020]. Disponible en: https:// www.paho.org/es/documentos/requerimientospara-uso-equipos-proteccion-personal-epp-paranuevo-coronavirus-2019-ncov

7. Andina Televisión [Internet]. Coronavirus en perú: Enfermeras de EsSalud denuncian falta de implementos, 2020 [Fecha de acceso: 11 de mayo 2020]. Disponible en: https://www.atv.pe/actualidad/enfermeras-deessalud-denuncian-falta-de-implementos-408705

8. Diario Gestión [Internet]. Coronavirus en Perú: Médicos de Hospital Goyoneche de Arequipa denuncian falta de protección, 2020 [Fecha de acceso: 8 de mayo 2020]. Disponible en: https:// gestion.pe/peru/coronavirus-en-peru-medicos-dehospital-goyoneche-de-arequipa-denuncian-faltade-proteccion-nnpp-noticia/ 